\title{
Epidemiology of mesothelioma in Egypt. A ten-year (1998-2007) multicentre study
}

\author{
Yosri Akl', Safy Kaddah', Ahmed Abdelhafeez ${ }^{1}$, Randa Salah², Mohamed Lotayef ${ }^{2}$
}

${ }^{1}$ Chest Diseases Department, Faculty of Medicine, Cairo University, Egypt 2Radiation Oncology Department, National Cancer Institute, Cairo University, Egypt

Submitted: 17 September 2009

Accepted: 4 February 2010

Arch Med Sci 2010; 6, 6: 926-931

DOI: 10.5114/aoms.2010.19303

Copyright $@ 2010$ Termedia \& Banach

\section{Abstract}

Introduction: Mesothelioma is a cancer strongly linked to exposure to carcinogenic minerals, especially asbestos. The aim of the study was to detect the incidence of malignant pleural mesothelioma (MPM) in Egypt, to clarify the impact of occupational and environmental risk factors, and to characterise its demographic features.

Material and methods: They were 584 cases diagnosed as MPM detected in Cairo University Hospitals and National Cancer Institute from 1998 to 2007. Unfortunately, full epidemiological data were only available for 165 cases due to absence of a reliable registration system.

Results: A steady increase in the number of cases was detected, from 24 in 1998, peaking at 82 cases in 2005, followed by a gradual decline (though still high) with 68 cases in 2006 and 51 cases in 2007. Male/female ratio was 1.35/1 ( $p>0.05$ ). The occupational exposure to asbestos was $13.9 \%$. Residential exposure plays a major role in two regions, Helwan and Shoubra $(27.3 \%$ and $20.6 \%$ respectively), while in Upper and Lower Egypt the level was $12.7 \%$ and $17.5 \%$ respectively. Kaplan-Meier survival for sex, residence and the pathological types epithelioid, biphasic and sarcomatoid was insignificant. The median survival for different grades and treatment modalities was significant $(P<0.001)$. Conclusions: There was a steady increase in the incidence of MPM from 1998 to 2005 followed by a decline during 2006-2007. Mesothelioma in Egypt is mainly concentrated in areas of high environmental pollution. The decline within the last 2 years may be attributed to recent strict industrial preventive measures. However, a better environmental control programme would benefit Egypt.

Key words: malignant pleural mesothelioma, epidemiology, asbestos

\section{Introduction}

Malignant pleural mesothelioma (MPM) is the most common malignant tumour of the pleura. Mesothelioma is a cancer that is linked to exposure to carcinogenic mineral fibres, especially asbestos and erionite. The possible role of other mineral fibres in causing mesothelioma is being investigated [1].

The incidence of mesothelioma has gone from almost none to the current 2500-3500 cases per year in the USA. Asbestos is considered the main cause of mesothelioma in the US and in the western world. It is proposed that as a consequence of the regulations to prevent exposure, to forbid and/or limit the use of asbestos, the incidence of mesothelioma in the US and in some European countries should have started to decline before or around the year 2000, and sharply decline thereafter [2].

\author{
Corresponding author: \\ Safy Kaddah, MD \\ Chest Diseases Department \\ Faculty of Medicine \\ Cairo University \\ Al-Saray Street \\ Cairo 11956 \\ Egypt \\ Fax: +20223687673 \\ E-mail: \\ safykaddah@yahoo.com
}


Epidemiological data prove that mesothelioma incidence in Egypt is rising markedly [3]. Since ancient times asbestos has been used in Egypt as it was known that ancient Egyptians used it in the mummification process [4]. There are 14 factories dealing with asbestos in Egypt. In Cairo, the most famous are the Siegwart factories (in Shobra ElKhaymah and Helwan districts), which produce both cement pipes and corrugated roofing panels reinforced with asbestos. Asbestos-based articles make up to $50-60 \%$ of their production. Also, the Ora Misr factory in the city of the $10^{\text {th }}$ of Ramadan (50 km east of Cairo) uses asbestos in the production process. In addition there is the Helwan factory, which was built in 1927 and started to produce asbestos articles in 1948, long before the discovery, in 1960, that asbestos can cause mesothelioma [5]. Asbestos is used in a variety of everyday products. Most people cannot even identify it, but, it is known that just several months of concentrated exposure to this substance can cause mesothelioma [6]. Although the lifetime risk of developing mesothelioma among asbestos workers is thought to be as high as 8 to $13 \%$, there is no direct correlation of pleural disease incidence with the amount or duration of asbestos exposure [7].

Simian virus 40 (SV40) infection and radiation exposure are additional causes [2]. Also, an exciting new discovery is that genetic susceptibility to mineral fibre carcinogenesis plays a critical role in the incidence of this cancer in certain families [8]. The clinical course of mesothelioma is steady deterioration to death over one to two years, although there is some evidence that patients with epithelial pattern have somewhat better prognosis over the other patterns [9]. The prospects for curative treatment are not good: management is either by surgery, radical radiotherapy or chemotherapy [10]. Other new therapeutic approaches include immunotherapy [10], gene therapy [11], hyperthermic chemoperfusion of the pleura [10] and photodynamic therapy [12], but the results have not yet been completely validated.

\section{Material and methods}

This retrospective study included all cases of MPM diagnosed in the period between 1998 and 2007 in the chest and nuclear medicine departments of Cairo University Hospitals as well as the National Cancer Institute, which represent two leading medical centres for diagnosis and treatment of cancer patients in Egypt.

The study was approved by the Human Ethics Committee of Cairo University and all subjects gave written informed consent before entry in the study.

The total number of cases was 584. There were 314 cases from the National Cancer Institute, 184 cases from the chest department, and 86 cases from the nuclear medicine department, Cairo University. Unfortunately, due to the poor recording system full epidemiological data were not found for all cases. Full epidemiological data were recorded for only 165 cases. Statistical description of each item was done according to availability of data.

\section{Statistical analysis}

Data were statistically described in terms of range, mean \pm standard deviation $( \pm S D)$, median, frequencies and percentages. Kaplan-Meier survival for different parameters was done. A probability value ( $P$ value) less than 0.05 was considered statistically significant. All statistical calculations were done using computer programs Microsoft Excel 2003 (Microsoft Corporation, NY, USA) and SPSS (Statistical Package for the Social Sciences; SPSS Inc., Chicago, IL, USA) version 15 for Microsoft Windows.

\section{Results}

In our study the total number of cases of MPM in the period from January 1998 to December 2007 was 584. The incidence of MPM showed a steady increase from 24 cases in 1998 to 82 cases in 2005 followed by a gradual decline to 51 cases in 2007 (Table I).

Full demographic data of the 165 cases showed that the mean age in the 165 cases was $50.78 \pm 13.5$ years, ranging from 15 to 83 years, 94 were males (57\%) and 71 were females (43\%), male/female ratio was 1.3/1 (Table II).

\section{Distribution of MPM by residence}

Out of the 165 cases, 45 (27.3\%) cases were reported from Helwan, followed by 34 (20.6\%) cases from Shobra and in the neighbouring areas of both, $25(15.2 \%)$ cases in Giza, and $11(6.7 \%)$ cases in Kaliobeya. From Upper Egypt 21 (12.7\%) cases were reported, and 29 (17.5\%) cases were from other parts of Egypt including Alexandria, Alesmaeleia,

Table I. Annual incidence of mesothelioma (1998-2007)

\begin{tabular}{|cccccccccccc|}
\hline & 1998 & 1999 & 2000 & 2001 & 2002 & 2003 & 2004 & 2005 & 2006 & 2007 & Total \\
\hline No. & 24 & 31 & 53 & 60 & 68 & 72 & 75 & 82 & 68 & 51 & 584 \\
\hline$\%$ & 4.11 & 5.31 & 9.08 & 10.27 & 11.65 & 12.33 & 12.84 & 14.04 & 11.65 & 8.72 & 100 \\
\hline
\end{tabular}


Alseweis, Algharbeia, Alsharqeia and areas in Cairo other than Helwan and Shobra (Table II).

\section{Distribution of MPM by occupation}

Concerning occupational risk factors only 23 (13.9\%) patients were working in asbestos industries such as cement pipes, roofing and wall materials, valves, joints, sealants, clothing, cords, strings, clutches, brake linings and pads as well as mine workers, while 142 (86.1\%) patients were not exposed to this hazard during working hours (Table II).

\section{Radiological features of MPM}

The main radiological features in most cases, 102 (61.8\%) cases of MPM, showed pleural thinking with typical finger-like projections and definitely pleural effusion which was usually unilateral and massive; out of them a single case showed in addition pericardial effusion. Pleural nodules were revealed in 54 (32.8\%) cases. Six (3.6\%) cases were proved by $\mathrm{CT}$ to have a large pleural mass with extrapleural extension to the chest wall. Two cases (1.2\%) presented with bilateral hilar lymphadenopathy in addition to a large pleural mass (Table III).

\section{Sampling techniques and histological diagnosis of MPM}

Thoracoscopy was done in 70 (42.4\%)cases, open pleural biopsy in 56 (33.9\%) cases, fine needle aspiration cytology (FNAC) in 10.3\% (17 cases), CT-guided biopsy in 9.1\% (15 cases), and Abram biopsy in $3.6 \%$ (6 cases). A single case was diagnosed by thoracocentesis $(0.6 \%)$.

Epithelioid mesothelioma represents the most common histopathological subtype of MPM diagnosed in 114 (69.1\%) cases, followed by biphasic subtype in $43(26.1 \%)$ and sarcomatoid type in

Table II. Demographic data of the 165 cases of MPM studied

\begin{tabular}{|llc|}
\hline Item & Parameter & $n(\%)$ \\
\hline Sex & M & $94(43)$ \\
\cline { 2 - 3 } & F & $71(57)$ \\
\cline { 2 - 3 } & Helwan & $45(27.3)$ \\
\cline { 2 - 3 } & Giza (area south of Helwan) & $15(15.2)$ \\
\cline { 2 - 3 } & Shoubra El-Khaymah & $34(20.6)$ \\
\cline { 2 - 3 } & $\begin{array}{l}\text { Kaliobeya } \\
\text { (area around Shoubra) }\end{array}$ & $11(6.7)$ \\
\cline { 2 - 3 } & Lower Egypt & $29(17.5)$ \\
\cline { 2 - 3 } & Upper Egypt & $23(12.7)$ \\
\hline $\begin{array}{l}\text { Occupational } \\
\text { risk }\end{array}$ & High & $142(86.1)$ \\
\cline { 2 - 3 } & Low & \\
\hline Total & & \\
\hline
\end{tabular}

$8(4.8 \%)$ cases. No case was diagnosed as desmoplastic.

Concerning grades of 165 cases, the commonest was grade II in 107 (64.8\%) cases, followed by grade III in 48 (29.1\%) cases and grade I in $10(6.1 \%)$ cases (Table III).

\section{Treatment modalities of MPM}

Regarding the treatment modalities of the 165 cases, chemotherapy alone was used in 58 (53.2\%) cases, surgery alone in 15 (9.1\%) cases, chemo-surgery in $43(26.1 \%)$ cases and palliative treatment in 49 (29.6\%) cases (10 cases received palliative radiotherapy).

Surgery was performed in 58 cases either alone or combined with chemotherapy, extrapleural pneumonectomy in 49 cases, out of which in addition pericardiectomy was performed in 3 cases, and excision of extrathoracic swelling in another 3 cases. Pleurectomy was the choice in 8 cases and metastasectomy in a single case (Table IV).

\section{Median survival of MPM patients (Kaplan-Meier)}

Overall survival of 165 cases ranged from one month to 52 months; the median survival duration

Table III. Collective radiological and pathological data of the 165 cases of MPM studied

\begin{tabular}{|c|c|c|c|}
\hline Item & \multicolumn{2}{|c|}{ Parameter } & $n(\%)$ \\
\hline \multirow{4}{*}{$\begin{array}{l}\text { Radiological } \\
\text { imaging }\end{array}$} & \multicolumn{2}{|c|}{ Pleural effusion \& thickening* } & $103(62.4)$ \\
\hline & \multicolumn{2}{|c|}{ Pleural nodules \& thickening } & $54(32.8)$ \\
\hline & \multicolumn{2}{|c|}{$\begin{array}{l}\text { Pleural mass with extrathoracic } \\
\text { extension }\end{array}$} & $6(3.6)$ \\
\hline & \multicolumn{2}{|c|}{$\begin{array}{l}\text { Hilar lymphadenopathy } \\
\& \text { pleural mass }\end{array}$} & $2(1.2)$ \\
\hline \multirow{6}{*}{$\begin{array}{l}\text { Biopsy } \\
\text { technique }\end{array}$} & \multicolumn{2}{|c|}{ Thoracoscopy } & $70(42.4)$ \\
\hline & \multicolumn{2}{|l|}{ Open } & $56(33.9)$ \\
\hline & \multicolumn{2}{|l|}{ FNAC } & $17(10.3)$ \\
\hline & \multicolumn{2}{|c|}{ CT-Guided } & $15(9.1)$ \\
\hline & \multicolumn{2}{|c|}{ Abram } & $6(3.6)$ \\
\hline & \multicolumn{2}{|c|}{ Thoracocentesis } & $1(0.6)$ \\
\hline \multirow[t]{7}{*}{ Pathology } & \multirow[t]{4}{*}{ Type } & Epithelioid & $114(69.1)$ \\
\hline & & Sarcomatoid & $8(4.8)$ \\
\hline & & Biphasic & $43(26.1)$ \\
\hline & & Desmoplastic & - \\
\hline & \multirow[t]{3}{*}{ Grade } & I & $10(6.1)$ \\
\hline & & II & $107(84.8)$ \\
\hline & & III & $48(29.1)$ \\
\hline Total & & & $165(100)$ \\
\hline
\end{tabular}

${ }^{*}$ A single case with pericardial effusion also 
was $7.0 \pm 0.5$ months. Kaplan-Meier survival analysis for all the studied parameters was done. The median survival for sex was $8.0 \pm 0.8$ months for females and $6.0 \pm 0.6$ months for males. It is statistically insignificant (Figure 1). The median survival for histopathological type was $9.8 \pm 9.2$ months for the epithelioid type, $7.1 \pm 4.8$ months for the biphasic type and $6.5 \pm 5.2$ months for the sarcomatoid type. These differences were statistically insignificant. The median survival for different grades was $6.0 \pm 4.7$ months for grade I, $8.0 \pm 0.7$ months for grade II and $5.0 \pm 0.5$ months for grade III. The difference is statistically significant $(P<0.001)$ (Figure 2). The median survival for the treatment modalities was $8.0 \pm 1.0$ months for chemotherapy alone, $3.0 \pm 0.9$ months for surgery alone, $11.0 \pm 0.7$ months for chemo-surgical treatment and $4.0 \pm 0.3$ months for supportive therapy. The difference is statistically significant $(P<0.001)$ (Figure 3).

\section{Discussion}

Our retrospective data were collected from the chest department and nuclear medicine department of Cairo University Hospitals in collaboration with the National Cancer Institute. There were 584 cases diagnosed as MPM on a histopathological basis during the period from January 1998 to December 2007. Full epidemiological data were only available for 165 cases due to absence of a reliable registration system. There was a steady increase in the number of cases up to 2005: the incidence of MPM showed a steady increase from 24 cases in 1998 to 82 cases in 2005 , followed by gradual decline to 51 cases in 2007. Our data support published data from the National Cancer Institute up to year 2005 that revealed a four-fold increase in the number of cases of MPM for the first five years of the third millennium in comparison to the number of cases reported over

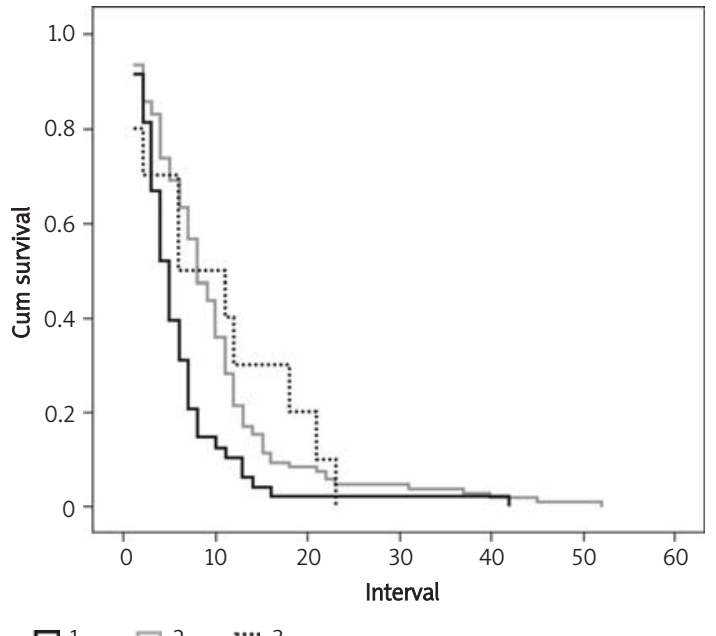

$\neg 1-\neg 2 \quad \ldots: \cdots: 3$

Figure 2. Kaplan-Meier survival for grades
Table IV. Descriptive data of therapeutic modalities of the 165 cases of MPM studied

\begin{tabular}{|llc|}
\hline & \multicolumn{1}{c}{ Type } & $n(\%)$ \\
\hline Management & Chemotherapy & $58(35.2)$ \\
\cline { 2 - 3 } & Surgical & $15(9.1)$ \\
\cline { 2 - 3 } & Chemo-surgical & $43(26.1)$ \\
\cline { 2 - 3 } & Palliative & $49(29.6)^{*}$ \\
\cline { 2 - 3 } & Total & $165(100)$ \\
\hline
\end{tabular}

*10 patients received palliative radiotherapy

the last ten years of the second millennium [3, 13-15]. Unfortunately, our number of cases of MPM detected does not represent the true actual incidence due to the absence of a reliable registration and case detection system in Egypt. Indeed, difficulties associated with the sampling and diagnosis, combined with the short survival time for MPM, may also be responsible for additional discrepancies.

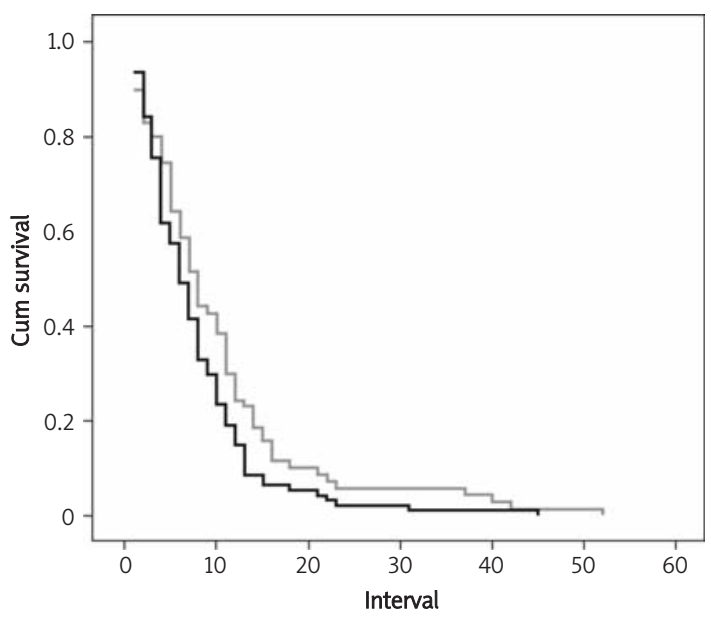

$\neg F-\neg M$

Figure 1. Kaplan-Meier survival for sex

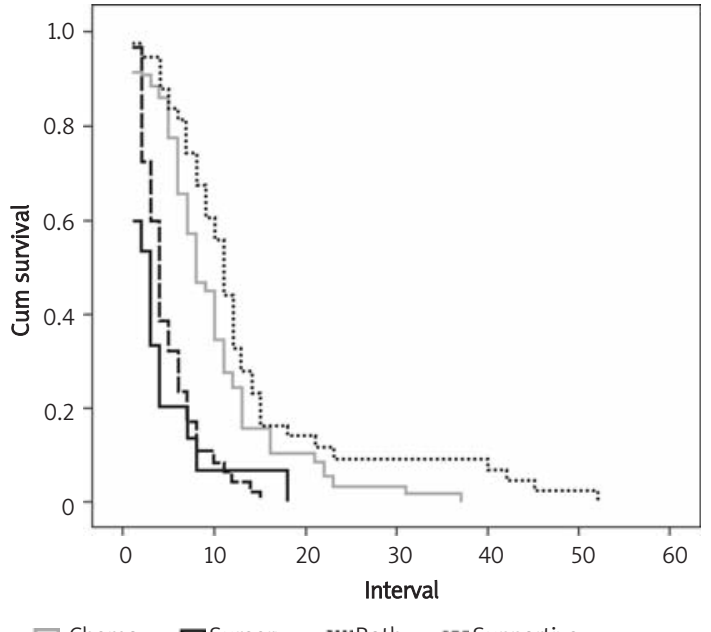

$\neg$ Chemo ـSurgery ....”: Both ...:";Supportive

Figure 3. Kaplan-Meier survival for treatment modalites 
In Egypt the application of stricter environmental preventive measures may explain the decline in the number of cases in the last two years. Unfortunately, there are no data available yet to support this work.

A large age range (15-83 years) was observed among the patients with MPM. The youngest was an adolescent (15 years), living in Kaliobeya, one of the regions associated with a high risk of mesothelioma. He had no associated occupational risk, was pathologically diagnosed with the epithelioid subtype, and died after 18 months. The median age of our patients was $50.78 \pm 13.5$ years, in contrast to that recorded in western countries, which is much higher, ranging from 60 to 69 years $[13,14]$. This difference is probably due to early residential and pollution exposure in Egypt [13].

The male/female ratio of our cases was 1.35/1; there was no major gender difference $(p>0.05)$. In contrast, in most western studies the male to female ratio was about $10: 1[16,17]$. This difference could be explained by the fact that most of our patients live in polluted areas, so the chance of exposure among both sexes is approximately equal, with a slight preponderance in males presumably due to spending more time outdoors in the vicinity of asbestos plants and other occupational hazards.

Occupational exposure to asbestos played a minor role in the epidemiology of MPM, as only $13.9 \%$ worked in industries related to asbestos, while the majority of patients (86.1\%) were not exposed to occupational risk. Residential exposure was found to play an important role, as most of the patients were living in highly polluted areas; $47.9 \%$ of our patients were living in Helwan and Shoubra, where Siegwart factories are present. In addition, $21.9 \%$ were living in neighbouring areas of these two regions. A study by Gafaar and Ally El-Din, 2005, has linked the high incidence of mesothelioma among people living in communities 5-7 kilometres from asbestos factories to industrial pollution. Neighbourhood exposure to asbestos was reported in over $80 \%$ of the cases of malignant mesothelioma treated at the National Cancer Institute in Cairo between 1989 and 1999 [13]. Our data confirm that pollution and environmental exposure to asbestos are a major issue as a cause of MPM rather than occupational exposure in Egypt. The limited occupational risk in our data may reflect better preventive industrial measures inside factories. However, a stricter adoption programme for environmental control in Egypt is still mandatory.

The radiological appearance of the 165 MPM cases was comparable to the findings from the literature $[10,18,19]$. The procedures used for diagnosing the 165 cases of MPM were thoracoscopy followed by open pleural biopsy, FNAC, CT-guided biopsy and Abram biopsy in $42.4 \%$,
$33.9 \%, 10.3 \%, 9.1 \%, 3.6 \%$ respectively. A single case was diagnosed by thoracocentesis and pleural fluid cytology despite the reported low sensitivity (26\%) of pleural fluid cytology to detect malignancy [10]. Medical thoracoscopy is now a common practice in the chest department of Cairo University Hospitals for diagnosis of pleural malignancy, since it has a sensitivity of $91 \%$ to $98 \%$ in detecting malignant pleural disease [10]. Currently, the most dominant histopathological type of MPM in Egypt is the epithelioid type followed by the biphasic and sarcomatoid type in $69.1 \%, 26.1 \%, 4.6 \%$ respectively. In our study no case showed desmoplastic pathological changes. These results are compatible with other studies reporting the highest frequency for epithelioid type and the lowest for sarcomatoid type $[10,13,16]$. Also, the most common treatment modality used was chemotherapy alone or with surgery (61.3\%) followed by supportive palliative treatment (29.6\%) and lastly surgery (9.1\%).

All our patients died. The median survival was $7.0 \pm 0.5$ months, the minimum was one month and the maximum was 52 months. Only in one reported case did the patient survive for about 4.5 years (52 months); the patient was 25 years of age, living in Helwan, with epithelioid subtype, grade II, and subjected to pleuropneumonectomy followed by chemotherapy.

Concerning the pathological type of our cases, the overall survival among the epithelioid subtype was about 10 months, for biphasic it was approximately 7 months, while for sarcomatoid it was approximately 6.5 months, and none of these differences in survival was statistically significant. De-Pangher et al. studied the relation between survival and histopathological type of MPM. The best survival was recorded in patients with the epithelioid and biphasic types; patients with the epithelioid type were categorized as a long-term survival group [20]. Currently, when comparing the overall survival to the modality of treatment, we found that the survival time for cases subjected to surgery was about 4 months, for cases receiving only supportive treatment was about 9 months, for cases receiving only chemotherapy was about 10 months, while for cases subjected to combined treatment was 13 months. These differences in survival time were statistically significant, being the best for patients receiving chemotherapy. These results match those obtained by Cicenas et al. who, in a study to detect the effect of treatment on MPM survival, found that mean survival time after combined treatment (chemotherapy and surgery) was $12 \pm 2$ months, compared with conservative treatment alone, $6.0 \pm 2$ months [21]. However, no randomized trial has yet demonstrated a group survival benefit for any mode of therapy or combination of therapeutic modalities over 
palliative care, and most patients with pleural mesothelioma, whether treated or untreated, will die of complications of local disease [22].

Several studies have mentioned that the median survival time was about 9.8 months depending on the series, while 5 -year survival is less than $5 \%$ [23-25]. In a large, population-based study, younger age at diagnosis, female gender and epithelioid histotype were all associated with significantly reduced hazard ratios. Calendar period of diagnosis, asbestos exposure and treatment were not associated with a statistically significant improvement in survival [25].

In conclusion, the incidence of MPM in Egypt steadily increased during 1998-2005, followed by a decline in the years 2006-2007. There is a positive link between residential location and the incidence of MPM, which is associated with areas of heavy pollution and environmental exposure to asbestos. Egypt should adopt more stringent controls to reduce pollution and rates of MPM. In addition, accurate recording and the development of a mandatory registration system are warranted to determine the true size and scope of this environmental problem in Egypt.

\section{References}

1. Granville L, Laga AC, Allen TC, et al. Review and update of uncommon primary pleural tumors. A practical approach to diagnosis. Arch Pathol Lab Med 2005; 129 : 1428-43.

2. Yang H, Testa JR, Carbone M. Mesothelioma epidemiology, carcinogenesis and pathogenesis. Curr Treat Options Oncol 2008; 9: 147-57.

3. Madkour M, Ally Eldin N, Mourad I. Environmental exposure to asbestos and the exposure-response relationship with mesothelioma. East Mediterr Health J 2009; 15: 25- 38.

4. Abratt R, Voriobiof D, White N. Asbestos and mesothelioma in South Africa. Lung Cancer 2004; 455: 53-60.

5. Wagner J, Sleggs C, Marchand P. Diffuse pleural mesotheliomas and asbestos exposure in the Northwestern Cape Province. Br J Ind Med 1960; 17 : 260-71.

6. De-Capitani E, Meitze K, Frazato-Junior C, et al. Malignant mesothelioma of the pleura with etiological association to asbestos exposure. Rev Assoc Med Bras 1997; 43: 265-72.

7. Abdel-Rahman NZ, Bahnassy AA, Mohamed WS, et al. Evaluation of simian virus- 40 as a biological prognostic Egyptian patients with malignant pleural mesothelioma. Pathol Int 2007; 57: 493-501.

8. Pietruska JR, Kane AB. SV40 oncoproteins enhance asbestos-induced DNA double-strand breaks and abrogate senescence in murine mesothelial cells. Cancer Res 2007; 67: 3637-45.

9. Hillerdal G. Pleural malignancies including mesothelioma. Curr Opin Pulm Med 1995; 1: 339-43.

10. Boutin C, Schlesser M, Frenay C, Astoul Ph. Malignant pleural mesothelioma. ERS Journals Ltd 1998; 12: 972-81.

11. Van Der Most RG, Robinson BW, Nelson DJ. Gene therapy for malignant mesothelioma: Beyond the infant years. Cancer Gem Ther 2006; 13: 897-904.
12. Ceresoli GL, Chiti A, Zucali PA, et al. Early response evaluation in malignant pleural mesothelioma by positron emission tomography with $18 \mathrm{~F}$-fluorodeoxyglucose. J Clin Oncol 2006; 24: 4587-93.

13. Gaafar RM, Ally Eldin NH. Epidemic of mesothelioma in Egypt. Lung Cancer 2005; 49 (Suppl. 1): S17-20.

14. Gaafar R, Mokhtar N, Ismail H, et al. molecular markers in malignant pleural mesothelioma. Lung Cancer 2003; 41: S17.

15. Mahgoub K. Environment and occupation as risk factors in a group of mesothelioma patients. Egypt J Occup Med 1999; 23: 55-67.

16. Beer TW, Shepherd P, Pullinger N. Immunostainig is related to prognosis in malignant mesothelioma. Histopathol 2001; 38: 515-41.

17. Vogelzang NJ, Rusthoven JJ, Symanowski J, et al. Phase III study of pemetrexed in combination with cisplatin vs. cisplatin alone in patients with malignant pleural mesothelioma. J Clin Oncol 2003; 21: 2636-44.

18. Whitley NO. Computed tomography and malignant mesothelioma. In: Antman K, Aisner J (eds.). Asbestosrelated Malignancy. Orlando, Grune and Stratton 1987; 265-99.

19. Kawashima A, Libshitz HI. Malignant pleural mesothelioma: CT manifestations in 50 cases. AJR Am J Roentgenol 1990; 155: 965 -9.

20. De-Pangher N, Manzini V, Brollo A, et al. Prognostic factors of malignant mesothelioma of the pleura. Cancer 1993, 72: 410-7.

21. Cicenas S, Zaremba S, Jakubauskiene R. Possibilities of diagnosis and treatment of malignant pleural mesothelioma. Medicina (Kaunas) 2004; 40 (Suppl. 1): 152-5.

22. Barriero TJ, Katzman PJ. Mesothelioma: a case presentation and review. J Am Osteopath Assoc 2006; 106: 699-704.

23. Antman KH, Shemin R, Ryan L, et al. Malignant mesothelioma: pronostic variables in a registry of 180 patients, the Dana-Farber Cancer Institute and Brigham and Women's Hospital experience over two decades 19651985. J Clin Oncol 1988; 6: 147-53.

24. Chahinian APH, Pajak TF, Holland JF, et al. Diffuse malignant mesothelioma (prospective evaluation of 69 patients). Ann Intern Med 1982; 96: 746-55.

25. Montanaro F, Rosato R, Gangemi M, et al. Survival of pleural mesothelioma in Italy: a population-based study. Int J Cancer 2009; 1: 201-7. 